\title{
Scope for growth of the estuarine mysid Neomysis integer (Peracarida: Mysidacea): effects of the organophosphate pesticide chlorpyrifos
}

\author{
S. D. Roast ${ }^{1}$, J. Widdows ${ }^{2}$, M. B. Jones ${ }^{1, *}$ \\ ${ }^{1}$ Plymouth Environmental Research Centre (Department of Biological Sciences), University of Plymouth, Drake Circus, \\ Plymouth, Devon PL4 8AA, United Kingdom \\ ${ }^{2}$ Centre for Coastal and Marine Sciences, Plymouth Marine Laboratory, Prospect Place, West Hoe, Plymouth, Devon PL1 \\ 3DH, United Kingdom
}

\begin{abstract}
Mysids (Peracarida: Mysidacea) are standard test organisms used routinely in acute tests to evaluate the comparative toxicity of chemicals to aquatic organisms. The criticism of such lethal measurements for ecosystem monitoring has resulted in a clear need for sub-lethal tests that enable a more comprehensive understanding of the potential impacts of toxicants on natural populations. Neomysis integer, the dominant mysid of the upper reaches of European estuaries, has relatively low $96 \mathrm{~h} \mathrm{LC}_{50}$ values for pesticides and trace metals, and is under investigation as a suitable species for monitoring the pollution status of European estuaries. In this paper, the effects of environmentally realistic concentrations of the organophosphate pesticide chlorpyrifos on some basic physiological processes of $N$. integer are evaluated as potential end points for indicators of environmental pollution. Oxygen consumption, egestion rate (used as a measure of fecding rate) and scope for growth (an integrated measure of the overall physiological status of an organism) were significantly affected by chlorpyrifos exposure. In contrast, absorption efficiency was unaffected by pesticide exposure. Chlorpyrifos effects were most pronounced following short (i.e. $48 \mathrm{~h}$ ) compared with longer exposure periods (e.g. $168 \mathrm{~h}$ ). Increased oxygen consumption was the most sensitive toxicity test end point for detecting chlorpyrifos exposure, however, this response may not apply to all toxicants. Reduced scope for growth and egestion rate are considered more representative of the effects of chlorpyrifos on natural mysid populations, but were only affected significantly at near-lethal exposure concentrations. All 3 responses were affected at concentrations lower than those currently acceptable by European Community legislation for potable waters
\end{abstract}

KEY WORDS: Neomysis integer Sub-lethal testing C Chlorpyrifos - Organophosphate pesticide

\section{INTRODUCTION}

Acute, lethal toxicity tests provide useful data on the comparative toxicity of chemical contaminants to aquatic biota but are of limited value for environmental management, particularly when the $\mathrm{LC}_{50}$ values are higher than the toxicant concentrations measured in the natural environment. Consequently, there is an increasing need to develop tests which measure sublethal responses to toxicants at environmentally realistic concentrations and which may be used to predict

•E-mail: mjones@plymouth.ac.uk environmental impact. Several physiological responses have been used to quantify the sub-lethal effects of contaminants on crustaceans. These include respiration (e.g. Gaudy et al. 1991), feeding (e.g. Crane \& Maltby 1991), excretion (e.g. McKenney \& Matthews 1990) and reproduction (e.g. McKenney \& Celestial 1996). In addition, 2 or more of these individual responses may be combined into a single, integrated bioassay such as 'scope for growth' (SFG) which provides a rapid, instantaneous measurement of the energy status of an organism (Widdows 1993). To date. there have been few attempts to compare different physiological responses of the same species to deter- 
mine which is the most sensitive, or most appropriate, for environmental monitoring (cf. Bamber \& Depledge 1997). In this paper, the effects of the pesticide chlorpyrifos $(0,0$-diethyl $0-3,5,6$-trichloro-2-pyridyl phosphorothioate), a non-systemic organophosphorothioate insecticide (Whitehead 1997), on the respiration, feeding, absorption efficiency and SFG of the estuarine mysid Neomysis integer (Leach) are compared. The potential of each parameter as a toxicity test end point is assessed. Surprisingly, although SFG has been reported for other peracarid crustaceans (e.g. the amphipod Gammarus pulex [Maltby et al. 1990]), it has not been evaluated previously for any mysid species.

Mysids (Crustacea: Peracarida) are used routinely in laboratory toxicity tests and the sub-tropical American species, Americamysis (=Mysidopsis) bahia, is a standard test organism adopted by the United States Environmental Protection Agency (USEPA) for marine and estuarine studies (e.g. USEPA 1987). Recent work has shown that $A$. bahia has limited tolerance to dilute salinity, casting doubt on its value as a test organism for use in estuaries (Pillard et al. 1999). More importantly, A. bahia is not representative of European estuaries and there is a clear need to identify an indigenous estuarine species for toxicity testing in Europe (e.g. NRA 1993). Neomysis integer, the dominant hyperbenthic mysid of the upper reaches of European estuaries (Mees et al. 1995, Mees \& Jones 1997), has relatively low $96 \mathrm{~h} \mathrm{LC}_{50}$ values for cadmium (3.9 $\mathrm{ug} \mathrm{l}^{-1}$ [Wildgust \& Jones 1998]) and the organophosphate pesticides chlorpyrifos and dimethoate $\left(0.14 \mu \mathrm{g} \mathrm{l}^{-1}\right.$ and $0.54 \mathrm{mg} \mathrm{l}^{-1}$ respectively [Roast et al. 1999a]). $N$. integer has been proposed as a test species for monitoring European estuaries (Emson \& Crane 1994, Roast et al, 1998a) and the present paper contributes further to this discussion.

\section{MATERIALS AND METHODS}

Mysid collection and maintenance. During March to May 1997, Neomysis integer were collected from the southern side of Terras Bridge, East Looe River Estuary (Cornwall, UK) (Roast et al. 1998b). Mysids were returned to the laboratory in habitat water (salinity = 1 psu) and placed in a shallow 15 l holding tank at a salinity of $10 \pm 1$ psu (made by combining filtered seawater and double-distilled, de-ionised water) in a constant-temperature room $\left(15 \pm 1^{\circ} \mathrm{C}\right)$. Water quality was maintained by an under-gravel filter. Lighting was provided at ambient laboratory levels by overhead fluorescent lights; a time switch provided a $16 \mathrm{~h} \mathrm{light:8 \textrm {h }}$ dark photoperiod. Mysids were fed ad libitum with $<48 \mathrm{~h}$ old Artemia sp. (Great Lakes, Utah) nauplii hatched in the laboratory from cysts.
Pesticide exposure regime. Mysids were exposed to chlorpyrifos concentrations of $0.038,0.056,0.072$ and $0.100 \mu \mathrm{g} \mathrm{I}^{-1}$ for 3 time periods $(48,96$ and $168 \mathrm{~h})$. Three pesticide concentrations were predicted to be sublethal, based on a $168 \mathrm{~h} \mathrm{LC}$ 50 estimate of $0.084 \mu \mathrm{g}$ chlorpyrifos $\mathrm{l}^{-1}$ for adult Neomysis integer (Roast et al. 1999a); $0.100 \mu \mathrm{g} \mathrm{l}^{-1}$ chlorpyrifos was included to examine pesticide effects at near lethal concentrations. Each chlorpyrifos concentration disrupts mysid swimming behaviour (Roast et al. 1999b). Due to the hydrophobic nature of chlorpyrifos [ $\log \mathrm{K}_{\text {ow }}=4.7$ (Whitehead 1997)], Distol grade acetone was used as a carrier for pesticide dosing (Roast et al. 1999a). An initial stock of $1 \mathrm{~g}$ chlorpyrifos $\mathrm{I}^{-1}$ acetone was diluted in series to produce a final stock concentration of $1 \mathrm{mg} \mathrm{l}^{-1}$ acetone; dilution water (salinity $=10$ psu) was made by combining filtered seawater and double-distilled, de-ionised water. Toxicant stock $(76,112,144$ or $200 \mu l)$ was injected via a Gilson pipette into the vortex of 11 of dilution water stirred at high speed in a 21 conical flask. Equalising volumes of acetone were injected into each vessel such that each had the same concentration of acetone (thus 124,88 , and $56 \mu$ acetone were injected into the 0.038 , 0.056 and $0.072 \mu \mathrm{g}$ chlorpyrifos $1^{-1}$ solutions, such that each exposure solution contained $100 \mu \mathrm{l}$ acetone $\mathrm{l}^{-1}$ ). Following 5 min mixing, the conical flask was filled to an accurately pre-marked 21 line to give the final concentrations required. In addition to the 4 pesticide exposure solutions, a solvent control (100 $\mu \mathrm{l}$ acetone $\mathrm{l}^{-1}$ ) was used to assess any effects of acetone on mysid physiology. As oxygen consumption by $N$. integer is gender specific (Roast et al. 1999c), only males were used in these experiment. For each exposure concentration, 10 mysids of equal length $(12 \pm 1 \mathrm{~mm}$ from the anterior margin of the rostrum to the tip of the telson) were placed together in 21 tall-form glass beakers containing $1500 \mathrm{ml}$ of exposure water. Due to the unstable nature of chlorpyrifos (ca 55\% loss within $24 \mathrm{~h}$ [Roast et al. 1999a]), exposure solutions were replaced every $24 \mathrm{~h}$ with a freshly made solution. At this time, dead or moribund mysids were removed from the test vessels (mortality was concentration dependent, and up to ca $60 \%$ had died after $7 \mathrm{~d}$ exposure to $0.1 \mu \mathrm{g}$ chlorpyrifos $\mathrm{l}^{-1}$ ). Mysids were fed ad libitum on $<48 \mathrm{~h}$ old Artemia sp. nauplii.

Measurement of oxygen consumption. Following exposure to chlorpyrifos for each time period $(48,96$ or $168 \mathrm{~h}$ ), a single mysid was placed in a $25 \mathrm{ml}$ perspex respiration chamber designed for 'closed' oxygen measurement (Roast et al. 1999c). Oxygen consumption was measured using Strathkelvin 1302 'Clark-type' polarographic electrodes and Strathkelvin 781 b oxygen meters, calibrated with oxygenfree nitrogen and air-saturated water, using values from dissolved oxygen tables (Green \& Carritt 1967). 
Oxygen consumption measurements were performed at $15 \pm 1^{\circ} \mathrm{C}$ (maintained by placing the respiration chamber in a temperature-controlled water bath) and at $10 \pm 1$ psu, using freshly made exposure solution of the same chlorpyrifos concentration to which the mysid had been exposed. Dissolved oxygen concentrations in each respiration chamber were measured for $2 \mathrm{~h}$ prior to introduction of the mysids to confirm stable DO levels in the test solutions. Following introduction into the respiration chamber, each mysid was allowed $1 \mathrm{~h}$ to acclimatise to the chamber, after which decline in dissolved oxygen concentration was recorded for $90 \mathrm{~min}$. After each experiment, mysids were removed from the test chambers, blotted dry and wet-weighed $( \pm 0.01 \mathrm{mg})$ using a Sartorius R200-D balance to allow weight-specific expression of oxygen consumption rates. Nine replicates were performed for each pesticide concentration and exposure period.

Measurement of egestion rate. Faecal production of Neomysis integer was measured, according to the method described by Roast et al.(1999d), from mysids feeding on sediment collected from the East Looe River Estuary. As mysid egestion rates correlate well with ingestion rates, the former is a valid, indirect measure of feeding rate (Murtaugh 1984). The organic content of the sediment food source in our experiments was low, giving further confidence to our use of egestion rate as an equivalent measure of feeding rate. Following exposure to chlorpyrifos, single mysids were placed in $2 \mathrm{l}$ tall-form beakers containing consolidated, pre-sieved sediment $(<63 \mu \mathrm{m})$ and $1 \mathrm{l}$ of freshly made exposure water of the same chlorpyrifos concentration to which each mysid had been exposed. Mysids were left to feed for $24 \mathrm{~h}\left(15^{\circ} \mathrm{C} ; 10 \pm 1 \mathrm{psu} ; 16 \mathrm{~h}\right.$ light: $8 \mathrm{~h}$ dark photoperiod), removed, placed in individual preweighed Eppendorf tubes and oven dried $\left(80^{\circ} \mathrm{C}\right)$ to constant weight $( \pm 0.01 \mathrm{mg})$. Faecal material was collected by re-suspension of the sediment in the glass beakers and passing the resultant suspension through a $120 \mu \mathrm{m}$ sieve. Faeces were rinsed with distilled water into glass test tubes and pipetted into individual, preweighed Eppendorf tubes. Faecal material was oven dried $\left(80^{\circ} \mathrm{C}\right)$ to constant weight $( \pm 0.01 \mathrm{mg})$ to allow weight-specific expression of egestion rates. Ten replicates for each pesticide concentration and exposure period were made.

Measurement of absorption efficiency. Mysid absorption efficiency was estimated by the ratio method (Conover 1966). Due to the extremely low weight of mysid faeces, faecal material from several mysids was pooled for the calculation of absorption efficiency. Oven-dried faecal material was placed into ashed, preweighed aluminium foil containers, ashed at $450^{\circ} \mathrm{C}$ for $2 \mathrm{~h}$ to combust fully the organic material and re- weighed $( \pm 0.01 \mathrm{mg})$ to ascertain the ash content of the faeces. Absorption efficiency was calculated using the equation:

$$
\text { Absorption efficiency }=(F-E) \div[(1-E) \times F]
$$

where: $F=$ ash-free dry weight:dry-weight ratio of food source, and $E=$ ash-free dry weight:dry-weight ratio of faeces (Conover 1966).

Calculation of scope for growth. Neomysis integer SFG was calculated by converting oxygen consumption and feeding rates into energy equivalents $\left(\mathrm{J} \mathrm{h}^{-1}\right)$, and calculating the net energy gain/loss through these physiological processes using the equation:

$$
P=A-(R+U)
$$

where: $P=\operatorname{SFG}\left(\mathrm{J} \mathrm{mg}\right.$ dry $\left.\mathrm{wt}^{-1} \mathrm{~h}^{-1}\right), A=$ energy absorbed $\left(\mathrm{J}\right.$ mg dry $\left.\mathrm{wt}^{-1} \mathrm{~h}^{-1}\right), R=$ energy respired $(\mathrm{J} \mathrm{mg}$ dry $\left.\mathrm{wt}^{-1} \mathrm{~h}^{-1}\right)$ and $U=$ energy excreted ( $\mathrm{J}$ mg dry $\mathrm{wt}^{-1}$ $\mathrm{h}^{-1}$ ) (Widdows \& Salkeld 1993). The relative components of this equation were calculated and transformed into energy equivalents as follows:

Energy absorbed:

$$
A=C \times \text { Absorption efficiency }
$$

where: $A$ = energy absorbed ( $\mathrm{J}$ mg dry $\mathrm{wt}^{-1} \mathrm{~h}^{-1}$ ) and $C$ = energy consumed $\left(\mathrm{J}\right.$ mg dry $\left.\mathrm{wt}^{-1} \mathrm{~h}^{-1}\right)$. The energy content of particulate organic matter is ca $23 \mathrm{~J} \mathrm{mg} \mathrm{ash-}$ free dry $\mathrm{wt}^{-1}$ (Widdows et al. 1979). Thus, in this instance, $C=$ egestion rate $\left(\mathrm{mg}\right.$ ash-free sediment $\mathrm{mg}^{-1}$ dry $w \mathrm{~h}^{-1}$ ) multiplied by 23 (Joules).

Energy respired:

$$
\begin{aligned}
R= & \text { oxygen consumption }\left(\mu \mathrm{l} \mathrm{O}_{2} \mathrm{mg} \mathrm{dry} \mathrm{wt}^{-1} \mathrm{~h}^{-1}\right) \\
& \times 0.02008
\end{aligned}
$$

where: $R=$ energy respired $\left(\mathrm{J} \mathrm{mg}\right.$ dry $\left.\mathrm{wt}^{-1} \mathrm{~h}^{-1}\right)$, oxygen consumption rates were converted to dry-weight specific rates by multiplying by 5 (mysid dry wt $=$ ca $20 \%$ mysid wet wt [Mauchline 1980]) and the heat equivalent of oxygen uptake $\left.=0.02008 \mathrm{~J}_{\left(\mu \mathrm{O}_{2}\right.}{ }^{-1}\right)$ (Gnaiger 1983). Mean dry-weight of mysids used in these experiments was ca $1.5 \mathrm{mg}$.

The rate of ammonia excretion is usually closely correlated with respiration rate and, contributing usually $<5 \%$ of metabolic energy expenditure, is usually omitted from the SFG calculation (Widdows \& Salkeld 1993). Ammonia excretion was not measured in the present study, thus SFG was calculated from the equation $P=A-R$ (units as defined above),

Statistical treatment of results. All statistical analyses were made using StatGraphics ${ }^{\circledR}$ Plus v3.1 (Statistical Graphics Corporation). Weight-specific rates of oxygen consumption were examined statistically by 1 and 2-way analysis of variance (ANOVA) to examine exposure concentration and exposure duration effects. Stepwise multiple linear regression analysis was ap- 


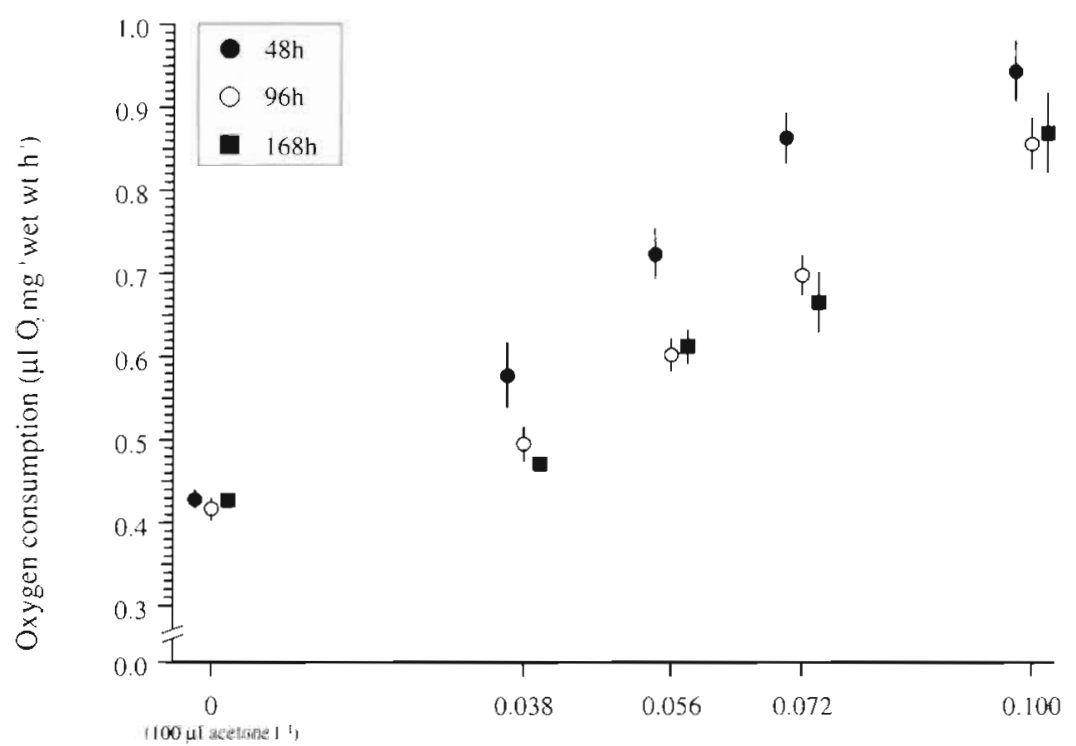

Exposure concentration ( $\mu \mathrm{g}$ chlorpyrifos $1^{-1}$ )

Fig. 1 Neomysis integer. Oxygen consumption following exposure to chlorpyrifos. $n=9$ for each exposure concentration/period. Error bars correspond to $95 \%$ confidence intervals

plied to the data to describe the relationship between oxygen consumption and pesticide exposure. Large, unexplained daily variation was recorded in mysid egestion rates; however, a multifactor ANOVA using 'day' as an experimental variable, showed that daily variation was not significant when all the data were analysed together (ANOVA, $F$-ratio $=0.36$, $\mathrm{df}=4, \mathrm{p}>0.1)$. Faecal material was pooled to calculate absorption efficiency data so no further analysis was possible. Scope for growth data are presented as means of the SFG calculated for 48,96 and $168 \mathrm{~h}$ exposure periods. ANOVA was used only on data that were normally distributed. Where significant $F$-ratios were calculated by ANOVA, Tukey's Honestly Significant Difference (HSD) test was applied to identify which datasets were different.

\section{RESULTS}

\section{Oxygen consumption rate}

Oxygen consumption by Neomysis integer was significantly affected by both exposure concentration (ANOVA, F-ratio $=718, \mathrm{df}=4, \mathrm{p}<0.001)$ and duration (ANOVA, $F$-ratio $=109, \mathrm{df}=$ $2, \mathrm{p}<0.001)$. Irrespective of exposure duration, exposure to chlorpyrifos resulted in significantly elevated rates of oxygen consumption by $N$. integer compared with control mysids (ANOVA, F-ratio $>200, \mathrm{df}=4, \mathrm{p}<$ $0.001)$. All chlorpyrifos concentrations caused increased oxygen consumption with a clear concentration response (HSD, $p<0.01$; Fig. 1). In addition to the concentration effect, duration of pesticide exposure also significantly affected mysid oxygen consumption rates (ANOVA, F-ratio $>7, \mathrm{df}=2, \mathrm{p}<0.01$ ). Mysids exposed to chlorpyrifos for $48 \mathrm{~h}$ had higher uptake rates than those exposed for 96 or $168 \mathrm{~h}$ (HSD, p < 0.01; Fig. 1), but there was no significant difference between oxygen consumption of mysids exposed for 96 or $168 \mathrm{~h}$ (HSD, p > 0.05; Fig. 1). Although there was a significant interaction between pesticide concentration and exposure period ( 2 -way ANOVA, $F$-ratio $=4.65, \mathrm{df}=6, \mathrm{p}<0.01)$, the effect was not obvious, and the individual effects of concentration and exposure period are considered more important.

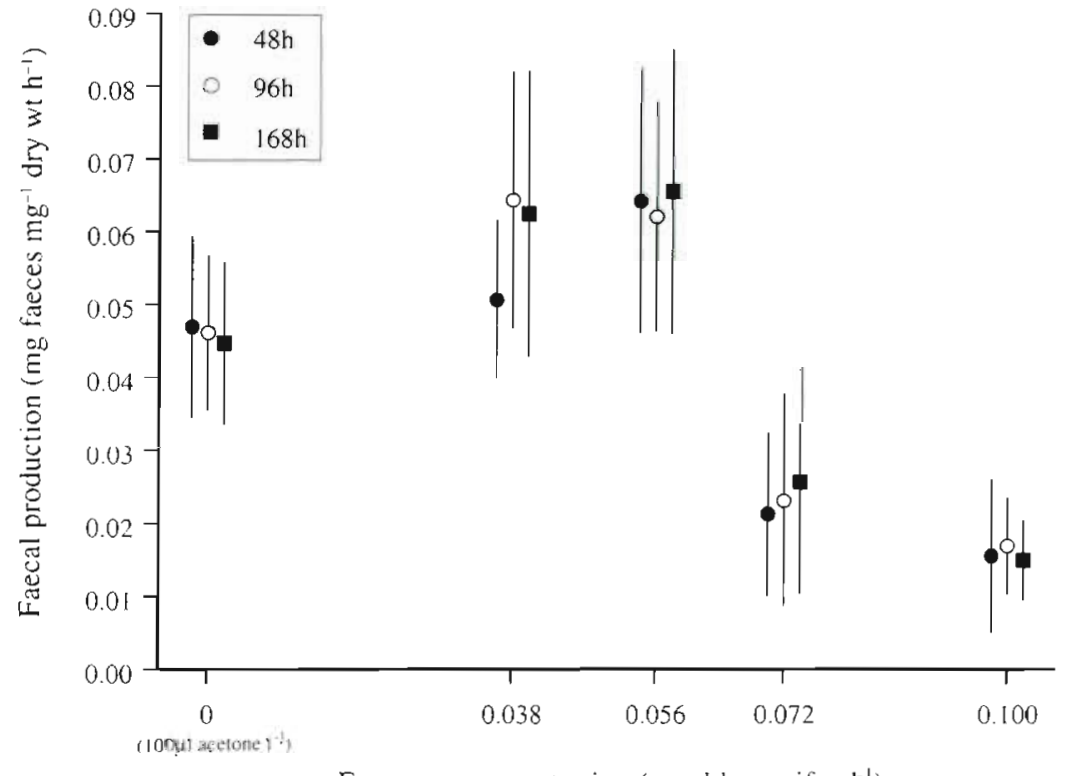

Exposure concentration ( $\mu g$ chlorpyrifos $\Gamma^{-1}$ )

Fig. 2. Neomysis integer. Egestion following exposure to chlorpyrifos. $\mathrm{n}=10$ for each exposure concentration/period. Error bars correspond to $95 \%$ confidence intervals 
Multiple linear regression analysis showed that concentration and exposure duration affected mysid oxygen consumption according to the equation:

$$
R=0.466+4.811 a-0.001 b
$$

where: $R=$ respiration rate $\left(\mu \mathrm{O} \mathrm{O}_{2} \mathrm{mg}\right.$ wet $\left.\mathrm{wt}^{-1} \mathrm{~h}^{-1}\right), a=$ exposure concentration ( $\mu \mathrm{g}$ chlorpyrifos $\mathrm{l}^{-1}$ ) and $b=$ exposure duration (h) $[\mathrm{p}<0.001$ (intercept); $\mathrm{p}<0.001$ (concentration); $\mathrm{p}<0.05$ (exposure duration); $\mathrm{R}^{2}=$ 0.901

\section{Egestion rate}

Egestion rates of Neomysis integer were significantly affected by chlorpyrifos concentration (ANOVA, $F$-ratio $=27.59, \mathrm{df}=4, \mathrm{p}<0.001$ ) but not by exposure duration (ANOVA, $F$-ratio $=0.72, \mathrm{df}=2, \mathrm{p}>$ 0.05). Follow up analysis using Tukey's HSD test showed that only exposure to the 2 higher pesticide concentrations led to egestion rates which were significantly different from control mysids. Mysids exposed to $0.072 \mu \mathrm{g}$ chlorpyrifos for $48 \mathrm{~h}$ had significantly reduced egestion rates compared with control mysids (HSD, p < 0.05); however, after 96 and $168 \mathrm{~h}$ exposure to $0.072 \mu \mathrm{g}$ chlorpyrifos $\mathrm{l}^{-1}$ egestion rates did not differ significantly from control rates (HSD, $p>0.05$ ) (Fig. 2). Egestion rates were significantly reduced following all 3 exposure periods at $0.1 \mu \mathrm{g}$ chlorpyrifos $1^{-1}$ (HSD, $p<0.01$ ) (Fig. 2). Although there appeared to be a trend of increased egestion rate following exposure to 0.038 and $0.056 \mu \mathrm{g}$ chlorpyrifos $\mathrm{l}^{-1}$ (Fig. 2), this was not significant (HSD, p > 0.05).

\section{Absorption efficiency}

Irrespective of exposure concentration and duration, the absorption efficiency of Neomysis integer was unaffected by chlorpyrifos (Fig. 3). Although pooling of material for calculation of the absorption efficiency prevented any statistical analysis, the absorption efficiencies of all pesticideexposed mysids were consistently within $1 \%$ of control mysid values (Fig. 3). Since there was a $1 \%$ variation about the mean ash-free dry weight of the natural sediment (used in the calculation of ash-ratio absorption efficiency), it is assumed that the small variations recorded in absorp- tion efficiency were due to experimental variation and not to pesticide exposure.

\section{Scope for growth}

Since different mysids were used to measure the individual components of the scope for growth calculations (i.e. oxygen consumption, feeding rate and absorption efficiency), scope for growth was estimated by entering the mean component values into Eqs. (2) to (4). True replicates were, therefore, not possible and a single SFG estimate was calculated for pesticide concentration and exposure period. However, with the exception of mysids exposed for $48 \mathrm{~h}$, there was no effect of exposure duration on the oxygen consumption or egestion rate of Neomysis integer, therefore, mean SFG values at each pesticide concentration were calculated by averaging SFG values at 48,96 and $168 \mathrm{~h}$, allowing comparison of concentration effects. Exposure to chlorpyrifos had a significant effect on SFG of $N$. integer (ANOVA, F-ratio $=61$, df $=4, p<0.01$ ) (Fig. 4). At the 2 higher pesticide concentrations, mysids had significantly reduced SFG compared with controls (HSD, p < 0.01; Fig. 4). The mean SFG for mysids exposed to $0.100 \mu \mathrm{g}$ chlorpyrifos $\mathrm{l}^{-1}$ was close to zero, with negative values for the lower $95 \%$ confidence interval, thus indicating that some mysids may have been utilizing more energy than they were assimilating (Fig. 4). Although the SFG of mysids exposed to

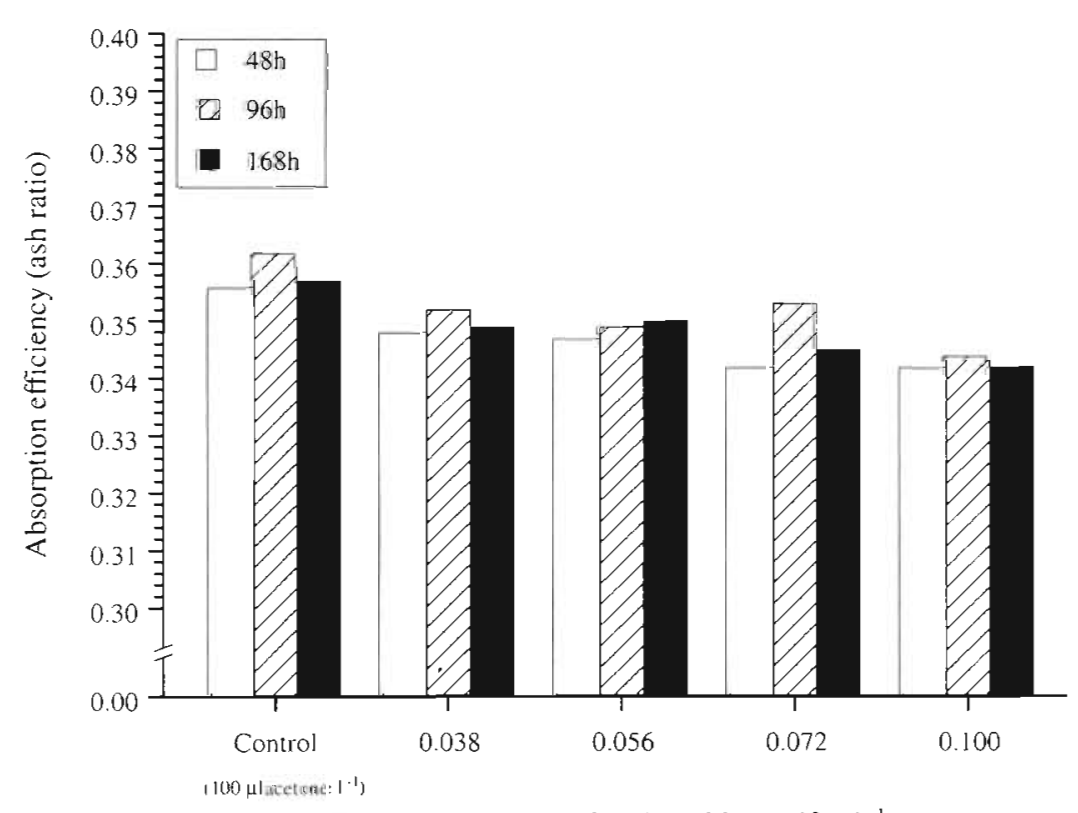

Exposure concentration ( $\mu \mathrm{g}$ chlorpyrifos $\mathrm{L}^{-1}$ )

Fig. 3. Neomysis integer. Absorption efficiency following exposure to chlorpyrifos. Each data set comprises pooled faecal material from 10 mysids 


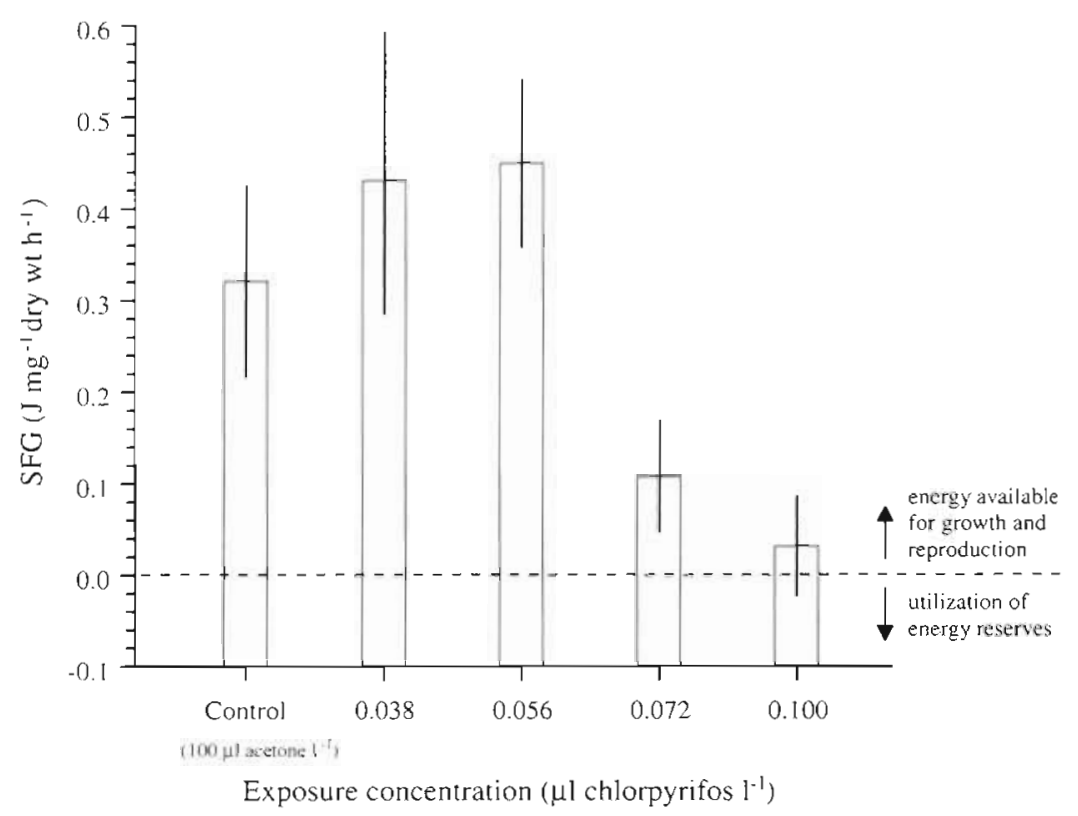

Fig. 4. Neomysis integer. Scope for growth (SFG) following exposure to chlorpyrifos. Data pooled from SFG calculated after 48, 96 and 168 h. Error bars correspond to $95 \%$ confidence intervals

been stimulated, resulting in more efficient metabolism and excretion of the pesticide. Monooxygenase systems are important in the metabolism of foreign organic compounds and are believed to play a role in the metabolism of organophosphate pesticides (WHO 1989). To our knowledge, monooxygenases have not been studied in mysids; however, there is a large literature reporting increased activity of these enzymes in decapod crustaceans following pollutant exposure (e.g. Lee 1991, Marsh et al. 1992, Ishizuka et al. 1996). Thus, it is likely that mysids also possess these systems.

Crustacean feeding rates are frequently suppressed following exposure to toxic contaminants (e.g. Crane \& Maltby 1991, Crane et al. 1995, Guerin \& Stickle 1995) and the feeding rate of Gammarus pulex has been proposed as a sensitive bioassay for quantifying sub-lethal effects of toxicants in freshwater environments (Crane \&

0.038 and $0.056 \mu \mathrm{g}$ chlorpyrifos $\mathrm{l}^{-1}$ appeared to increase compared with control mysids, this increase was not significant (HSD, p>0.05; Fig. 4).

\section{DISCUSSION}

In the present study, the oxygen consumption of Neomysis integer exposed to each chlorpyrifos concentration increased compared with control mysids. There was a clear concentration response and mysids exposed to $0.1 \mu \mathrm{g}$ chlorpyrifos $l^{-1}$ consumed oxygen at twice the rate of control mysids. Increased rates of oxygen consumption have been reported previously for mysids exposed to toxic contaminants. For example, oxygen consumption of $N$. americana exposed to naphthalene increased compared with rates of control mysids (Smith \& Hargreaves 1984), and oxygen consumption by Americamysis bahia increased following exposure to the pesticides thiobencarb and fenthion (McKenney 1985, McKenney \& Matthews 1990). In addition to the concentration response, there was also an exposure period effect, where mysids exposed to chlorpyrifos for $48 \mathrm{~h}$ consumed oxygen at a greater rate than mysids exposed for 96 or $168 \mathrm{~h}$. The reasons for these differences are unclear, although it may be linked, in part, with pesticide detoxification. Following $48 \mathrm{~h}$ exposure, mysids may be responding to the physiological stress of acute pesticide poisoning, whereas at 96 and $168 \mathrm{~h}$, detoxification mechanisms may have
Maltby 1991). Few studies have investigated the effects of toxicants on mysid feeding rates, although following exposure to cadmium the feeding rate of Leptomysis lingrura decreased by almost $50 \%$ compared with control mysids (Gaudy et al. 1991). The egestion rate of Neomysis integer (and, therefore, feeding rate) following exposure to chlorpyrifos was significantly affected by pesticide concentration and exposure duration. Mysids exposed to $\geq 0.072 \mu \mathrm{g}$ chlorpyrifos $l^{-1}$ had decreased egestion rates compared with control mysids. As with oxygen consumption, the effects of chlorpyrifos on mysid egestion rate were greatest after the shortest exposure period (i.e. $48 \mathrm{~h}$ ) possibly due to the induction of pesticide metabolism during this period. However, at $0.100 \mu \mathrm{g} \mathrm{l}^{-1}, N$. integer egestion rates were significantly suppressed compared with controls, presumably because rate of uptake was greater than the rate of metabolism/excretion of the pesticide.

In contrast to egestion rate, the absorption efficiency of Neomysis integer appeared to be unaffected by exposure to chlorpyrifos. There are limited published values on the effects of toxic chemicals on mysid absorption efficiencies, except that cadmium lowered the absorption efficiency of Leptomysis linguura by ca $9 \%$ compared with controls (Gaudy et al. 1991). In the present study, the comparative stability of the absorption efficiency of $N$. integer may be related to the low organic content of the sediment provided as a food source, which was likely to have a high refractile com- 
ponent. In general, absorption efficiency is less sensitive to toxicant exposure than actual feeding rates and ingestion rate is considered the most important process in energy acquisition (e.g. Crane \& Maltby 1991).

Clearly, present results indicate that chlorpyrifos exposure has significant effects on the energy expenditure/acquisition of Neomysis integer. The increased rate of oxygen uptake by $N$. integer following exposure to chlorpyrifos thus leads to increased energy expenditure (the heat equivalent of oxygen uptake is

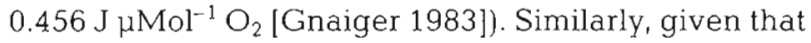
absorption efficiency was unaffected by exposure to chlorpyrifos, suppression of egestion rate (and thus ingestion rate) following pesticide exposure will lead to reduced energy acquisition. The calculation of SFG incorporates all the various components of an organism's energy budget by transformation of these rates into energy equivalents (i.e. Joules $\mathrm{h}^{-1}$ ) (Widdows \& Salkeld 1993). Energy gained by feeding and absorption is compared with energy lost through respiration and excretion, thus identifying the overall physiological effect of chlorpyrifos on $N$. integer. In the present study, the SFG of $N$. integer was dependent upon the concentration of chlorpyrifos. Control $N$. integer (at $15^{\circ} \mathrm{C}$ and $10 \mathrm{psu}$ ) had a mean SFG of $0.32 \mathrm{~J} \mathrm{mg}^{-1}$ dry wt $\mathrm{h}^{-1}$ and this value compares well with previous SFG estimates (Roast 1997). Exposure to 0.038 and $0.056 \mu \mathrm{g}$ chlorpyrifos $\mathrm{l}^{-1}$ tended to increase the SFG compared with control mysids, although this was not statistically significant. In contrast, exposure to 0.072 and $0.100 \mu \mathrm{g}$ chlorpyrifos $l^{-1}$ led to a marked reduction in SFG compared with control mysids. Furthermore, mysids exposed to $0.100 \mu \mathrm{g}$ chlorpyrifos $\mathrm{l}^{-1}$ had a mean SFG close to zero, and the lower $95 \%$ confidence limit was negative, indicating that some mysids had negative SFG and were probably utilizing energy reserves. In general, SFG declines in organisms exposed to toxicants (Widdows 1993); however, this conclusion is based mainly on studies of bivalve molluscs (e.g. Widdows \& Donkin 1992, Widdows et al. 1995). To our knowledge, SFG per se has not been reported previously for mysids. The reduced food consumption and absorption efficiency of Leptomysis lingvura following exposure to cadmium (Gaudy et al. 1991), however, suggests that the SFG of this mysid would have been reduced in response to cadmium exposure. In the present study, SFG of $N$. integer decreased due to toxic effects of the pesticide poisoning; however, it is likely that such contamination in the natural environment would have even greater effects than those recorded here. The estuarine environment is a dynamic system and mysids have to swim for much of the time to maintain their optimum position (Roast et al. 1998b). Hence, the oxygen consumption of swimming mysids will be higher than that of mysids at rest (as they were in this study) and the energy expenditure of mysids in their natural environment will be greater than the value calculated in the present study. In the natural environment, exposure of $N$. integer to $\geq 0.072 \mu \mathrm{g}$ chlorpyrifos $\mathrm{I}^{-1}$, and the subsequent suppression of the feeding rate, would cause a loss in energy acquisition leading to reduced energy available for swimming and growth.

One final consideration is to assess which of the physiological responses measured in the present study offers the best potential for regulatory or environmental assessment purposes. Oxygen consumption was the most sensitive response and increased following exposure to the lowest pesticide concentration $(0.038 \mu \mathrm{g}$ chlorpyrifos $\mathrm{l}^{-1}$ ) used. Egestion rate and, not surprisingly, SFG (as it is dependent on feeding rate) were affected only following exposure to 0.072 and $0.100 \mu \mathrm{g}$ chlorpyrifos $\mathrm{l}^{-1}$. All 3 responses were concentrationdependent and thus have potential as measures of pollutant effects on estuarine ecosystems. Clearly, in energetic terms, SFG, would be the most appropriate response to measure, since it represents how much Neomysis integer can grow and reproduce or how close it is to the limit of growth and survival (i.e. it provides a measure of fitness or the 'assimilation' capacity of the species). While oxygen consumption is affected at lower chlorpyrifos concentrations than egestion. (= feeding) rate and SFG, and can thus provide an earlier detection of a response to toxicants, it is difficult to interpret as it is an isolated physiological response. For example, both increases and decreases can be regarded as beneficial (i.e. enhanced costs associated with growth or energy consumption) or detrimental (i.e. metabolism of a toxicant or toxicant inhibition of metabolic pathways). Scope for growth and feeding rate of $N$. integer were only disrupted by chlorpyrifos concentrations approaching those causing lethal effects, especially for the longer exposure periods used in the present study. For example, egestion rate was significantly reduced following $48 \mathrm{~h}$ exposure to $0.072 \mu \mathrm{g}$ chlorpyrifos $\mathrm{l}^{-1}$ compared with the $48 \mathrm{~h} \mathrm{LC}_{50}$ of $0.30 \mu \mathrm{g}$ chlorpyrifos $\mathrm{l}^{-1}$ (Roast et al. 1999a). However, after 96 and 168 h exposure to chlorpyrifos, the difference between the sub-lethal and lethal effect concentrations was significantly reduced. Egestion rate was reduced at $0.1 \mu \mathrm{g}$ chlorpyrifos $\mathrm{l}^{-1}$ which was only just below the $96 \mathrm{~h} \mathrm{LC} 50$ value $\left(0.14 \mu \mathrm{g}\right.$ chlorpyrifos $\mathrm{l}^{-1}$ [Roast et al. 1999a]) and is greater than the $168 \mathrm{~h} \mathrm{LC}_{50}$ $\left(0.084 \mu \mathrm{g}\right.$ chlorpyrifos $\mathrm{l}^{-1}$ [Roast et al. 1999a]). This narrow range between sub-lethal (SFG) and lethal concentrations may be a feature of active (motile) crustaceans in contrast to sessile bivalves where SFG is affected at much lower toxicant concentrations than those causing mortality (Widdows \& Donkin 1992). Oxygen consumption, however, was disrupted at chlorpyrifos concentrations an order of magnitude 
lower than those causing lethal effects. Exposure to these low concentrations of chlorpyrifos (e.g. $0.038 \mu \mathrm{g}$ $1^{-1}$ ) also disrupted the swimming behaviour and speed of $N$. integer (Roast et al. 1999b). Chlorpyrifos is a neurotoxin and disruption of swimming behaviour is consistent with its mode of action on the nervous system. The increased oxygen consumption of $N$. integer following exposed to chlorpyrifos may be coupled to the effects on mysid swimming activity, in particular stamina, due to increased energetic demands. Thus position maintenance in the estuarine environment is likely to be more energetically demanding for chlorpyrifos exposed mysids, perhaps to the extent where they are unable to maintain position in the lower salinity, upper part of the estuary.

Currently, chlorpyrifos levels in British waters are not monitored routinely; however, its usage in the UK is significant (Thomas et al. 1997). For example, in 1996, an estimated 34 tonnes of chlorpyrifos were applied to 52,156 ha of arable crops in Great Britain (Thomas et al. 1997). European Community (EC) legislation allows up to $0.1 \mu \mathrm{g} \mathrm{l}^{-1}$ of any single pesticide and up to $0.5 \mu \mathrm{g}$ $\mathrm{I}^{-1}$ total pesticide loading in potable waters (Council of European Communities 1980). Few member countries actually achieve these criteria (Murgatroyd \& Patel 1994) and have their own interim maximum levels which exceed EC recommendations (especially for non-potable waters). The present study suggests that these maximum levels are too high, since chlorpyrifos affected the physiology of Neomysis integer at concentrations lower than even those stated by the EC for potable waters.

In summary, exposure to chlorpyrifos caused significant effects on the physiology of Neomysis integer. Although oxygen consumption was a more sensitive response than egestion rate and SFG (for chlorpyrifos), it is unknown whether it is a consistent response to a wide range of toxicants. Scope for growth, however, provides more information concerning likely environmental effects of toxic contaminants. All 3 responses were significantly affected at concentrations lower than those currently allowed by European legislation for potable water.

Acknowledgements. This work was conducted whilst SDR was in receipt of a Natural Environment Research Council C.A.S.E. studentship with the Brixham Environmental Laboratory (ZENECA Limited) (Studentship No. GT4/94/399/A) for which we are grateful.

\section{LITERATURE CITED}

Bamber SD, Depledge MH (1997) Evaluation of changes in the adaptive physiology of shore crabs (Carcinus maenas) as an indicator of pollution in estuarine environments. Mar Biol 129:667-672
Conover RJ (1966) Assimilation of organic matter by zooplankton. Limnol Oceanogr 11:338-345

Council of European Communities (1980) Directive relating to the quality of water intended for human consumption. No. 80/778/EC

Crane M. Maltby L (1991) The lethal and sublethal responses of Gammarus pulex to stress: sensitivity and sources of variation in an in situ bioassay. Environ Toxicol Chem 10: $1331-1339$

Crane M, Delaney P, Watson S, Parker P, Walker C (1995) The effect of Malathion 60 on Gammarus pulex (L.) below water cress beds. Environ Toxicol Chem 14:1181-1189

Emson S, Crane M (1994) A comparison of the toxicity of cadmium to the mysid shrimps Neomysis integer (Leach) and Mysidopsis bahia (Molenock). Water Res 28:1711-1713

Gaudy R, Guérin JP, Kerambrun P (1991) Sublethal effects of cadmium on respiratory metabolism, nutrition, excretion and hydrolyse activity in Leptomysis lingvura (Crustacea: Mysidacea). Mar Biol 109:493-501

Gnaiger E (1983) Heat dissipation and energetic efficiency in animal aboxibiosis: economy contra power. J Exp Zool 228:471-490

Green EJ, Carritt DE (1967) New tables for oxygen saturation of seawater. J Mar Res 25:140-147

Guerin JL, Stickle WB (1995) Effects of cadmium on survival, osmoregulatory ability and bioenergetics of juvenile blue crabs Callinectes sapidus at different salinities. Mar Environ Res 40:227-246

Ishizuka M, Hoshi H, Minamoto N, Masuda M, Kazusaka A. Fujita S (1996) Alterations of cytochrome P450-dependent monooxygenase activities in Eriocheir japonicus in response to water pollution. Environ Health Perspect 104:774-778

Lee RF (1991) Metabolism of tributyltin by marine animals and possible linkages to effects. Mar Environ Res 32 $29-35$

Maltby L, Naylor C, Calow P (1990) Effect of stress on a freshwater benthic detritivore. Scope for growth in Gammarus pulex. Ecotoxicol Environ Saf 19:285-291

Marsh JW, Chipman JK, Livingstone DR (1992) Activation of xemobiotics to reactive and mutagenic products by the marine invertebrates Mytilus edulis, Carcinus maenas and Asterias rubens. Aquat Toxicol 22:115-128

Mauchline J (1980) The biology of mysids. Adv Mar Biol 18 : $1-369$

McKenney CL Jr (1985) Associations between physiological alterations and population changes in an estuarine mysid during chronic exposure to a pesticide. In: Vernberg FJ, Thurberg FP, Calabrese A, Vernberg WB (eds) Marine pollution and physiology: recent advances. University of South Carolina Press, Columbia, p 397-4.18

McKenney CL Jr, Celestial DM (1996) Modified survival, growth and reproduction in an estuarine mysid (Mysidopsis bahial exposed to a juvenile hormone analogue through complete life-cycle. Aquat Toxicol 35:11-20

McKenney CL Jr, Matthews E (1990) Alterations on the energy metabolism of an estuarine mysids (Mysidopsis bahia) as indicators of stress from chronic pesticide exposure. Mar Environ Res 30:1-19

Mees J, Jones MB (1997) The hyperbenthos. Oceanogr Mar Biol Annu Rev 35:221-255

Mees J, Fockedey N, Hamerlynck O (1995) Comparative study of the hyperbenthos of three European estuaries Hydrobiol 311:153-174

Murgatroyd C, Patel A (1994) Proposed environmental quality standards for dimethoate and omethoate in water (DWE 9026). Final report to the Department of the Environment. WRc, Marlow 
Murtaugh PA (1984) Variable gut residence time: problems in inferring feeding rate from stomach fullness of a mysid crustacean. Can J Fish Aquat Sci 41:1287-1293

NRA (1993) The development of an estuarine toxicity test using an indigenous mysid. Research and Development Note 172. National Rivers Authority, Bristol

Pillard DA, DuFresne DL, Tietge JE, Evans JM (1999) Response of mysid shrimp (Mysidopsis bahia), sheepshead minnow (Cyprinodon variegatus), and inland silverside minnow (Menidia beryllina) to changes in artificial seawater salinity. Environ Toxicol Chem 18:430-435

Roast SD (1997) Ecophysiology of Neomysis integer (Peracarida: Mysidacea). PhD Thesis, University of Plymouth

Roast SD, Thompson RS, Widdows J, Jones MB (1998a) Mysids and environmental monitoring: a case for their use in estuaries. Mar Freshw Res 49:827-832

Roast SD, Widdows J, Jones MB (1998b) The position maintenance behaviour of Neomysis integer (Peracarida: Mysidacea) in response to current velocity, substratum and salinity. J Exp Mar Biol Ecol 220:25-45

Roast SD, Thompson RS, Donkin P, Widdows J, Jones MB (1999a) Toxicity of the organophosphate pesticides chlorpyrifos and dimethoate to Neomysis integer (Crustacea: Mysidacea). Water Res 33:319-326

Roast SD, Widdows J, Jones MB (1999b) Disruption of swimming in the hyperbenthic mysid Neomysis integer (Peracarida: Mysidacea) by the organophosphate pesticide chlorpyrifos. Aquat Toxicol (in press)

Roast SD, Widdows J, Jones MB (1999c) Respiratory responses of the estuarine mysid Neomysis integer (Peracarida: Mysidacea) in relation to a variable environment. Mar Biol 133:643-649

Roast SD. Widdows J, Jones MB (1999d) Egestion rates of the estuarine mysid Neomysis integer (Peracarida: Mysidacea) in relation to a variable environment. J Exp Mar Biol Ecol (in press)

Smith RL, Hargreaves BR (1984) Oxygen consumption in

Editorial responsibility: Otto Kinne (Editor),

Oldendorf/Luhe, Germany
Neomysis americana (Crustacea: Mysidacea) and the effects of naphthalene exposure. Mar Biol 79:109-116

Thomas MR, Garthwaite DG, Banham AR (1997) Pesticide usage survey report 141 -arable farm crops in Great Britain 1996. MAFF, London

USEPA (1987) Short-term methods for estimating the chronic toxicity of effluents and receiving waters to marine and estuarine organisms. EPA 600/4-87-028, United States Environmental Protection Agency, Cincinnati, $\mathrm{OH}$

Whitehead, R (1997). The UK Pesticide Guide 1997 CAB International and British Crop Protection Council. University Press, Cambridge

WHO (1986) Environmental Health Criteria 63: Organophosphorothioate Pesticides-a general introduction. International programme on chemical safety. World Health Organisation, Geneva

Widdows J (1993) Marine and estuarine toxicity tests. In Calow P (ed) Handbook of ecotoxicology. Blackwell, Oxford, p 145-166

Widdows J, Donkin P (1992) Mussels and environmental contaminants: bioaccumulation and physiological aspects. In Gosling EM (ed) The mussel Mytilus. Elsevier, Amsterdam, p 383-424

Widdows J, Salkeld PN (1993) Practical procedures for the measurement of scope for growth. MAP Tech Rep Ser 71 $147-172$

Widdows J, Moore MN, Lowe DM, \& Salkeld PN (1979) Some aspects of a dinoflagellate bloom (Gyrodinium auroleum) on the mussel Mytilus edulis. J Mar Biol Assoc UK 59: 522-524

Widdows J, Donkin P, Brinsley MD, Evans SV, Salkeld PN, Franklin A, Law RJ, Waldock MJ (1995) Scope for growth and contaminant levels in North Sea mussels Mytilus edulis. Mar Ecol Prog Ser 127:131-148

Wildgust M, Jones MB (1998) Salinity change and the toxicity of the free cadmium ion $\left[\mathrm{Cd}^{2+}{ }_{(a q)}\right]$ to Neomysis integer (Crustacea: Mysidacea). Aquat Toxicol 41:187-192

Submitted: April 4, 1999; Accepted: October 26, 1999 Proofs received from author(s): December 13, 1999 